\title{
Effect of Co-Existing Covalent Cross-Links on The Properties of Rotaxane-Cross-Linked Polymers
}

\author{
Jun Sawada ${ }^{1}$, Daisuke Aoki ${ }^{1}$, Yilin Sun ${ }^{1}$, Ken Nakajima ${ }^{1}$, and Toshikazu Takata ${ }^{1,2 *}$ \\ Email (Corresponding Author) ttakata@polymer.titech.ac.jp
}

${ }^{1}$ Department of Chemical Science and Engineering, Tokyo Institute of Technology, Ookayama, Meguro, Tokyo 152-8550, Japan

${ }^{2}$ School of Materials and Chemical Technology, Tokyo Institute of Technology, 4259 Nagatsuta-cho, Midori-ku, Yokohama 226-8503, Japan

\section{Table of Contents}

\section{Experimental}

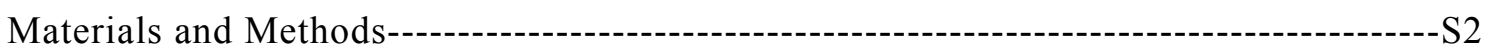

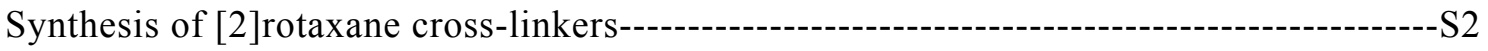

Synthesis of cross-linked polymers---

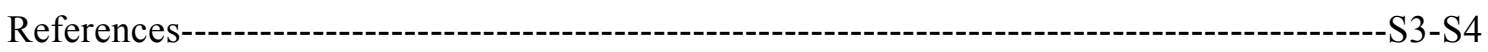




\section{Experimental}

\section{Materials and Methods}

Dichloromethane was purchased from ASAHI GLASS CO., LTD., and washed with water and dried with $\mathrm{MgSO}_{4}$ and then Molecular Sieves 4A (Wako Pure Chemical Industries, LTD.). Commercially available 1,6-hexanediol dimethacrylate (98\%, TCI: Tokyo Chemical Industry Co., LTD.) and $n$-butyl acrylate (BA) $(99 \%, \mathrm{TCI})$ were used without further purification. Other commercially available reagents and solvents were used as received.

The UV irradiation was carried out with a high pressure mercury lamp OPM2-250H (USHIO INC.). Tensile tests were performed using a Shimadzu EZ-Test instrument in uniaxial tension at a cross-head speed of $10 \mathrm{~mm} / \mathrm{min}$ at room temperature. Samples were prepared by using a punching blade (SDMP-1000, DUMBBELL CO., LTD.) conformed to ISO 37-4 specimens (dumbbell shape, $12 \mathrm{~mm} \times 2 \mathrm{~mm}$ ).

Swelling experiments were performed with 5.0-15 mg of cross-linked polymers which were immersed in $\mathrm{CHCl}_{3}$ (ca. $5.0 \mathrm{~mL}$ ) at r.t. The swelling ratio was defined as the difference in weight of the swollen gel $\left(W_{\text {swollen }}\right)$ vs. the dried gel $\left(W_{\text {dry }}\right)$, as calculated according to equation (1).

$$
\text { Swelling ratio [\%] }=\frac{W_{\text {swollen }}-W_{\text {dry }}}{W_{\text {dry }}} \times 100
$$

\section{Synthesis of [2] rotaxane cross-linker (RC)}
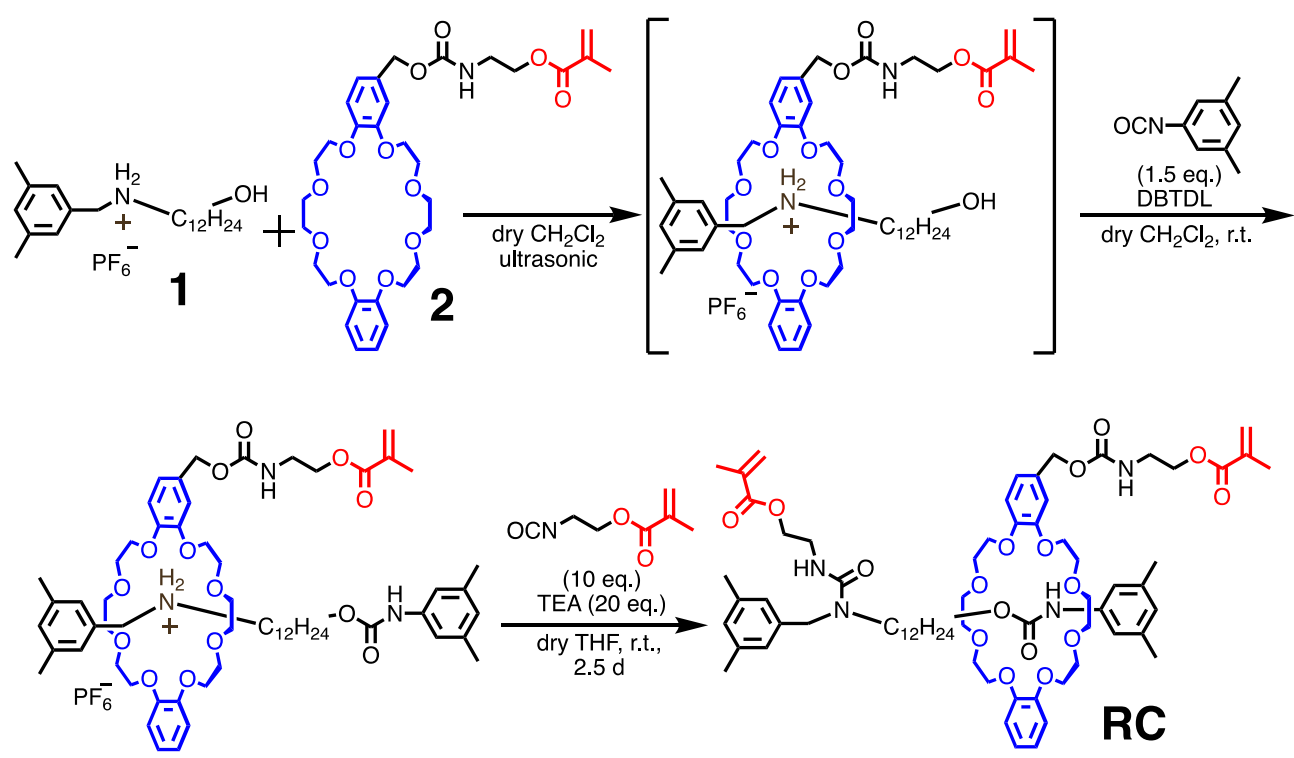

Axle component with a hydroxyl group (1) was synthesized according to the previously reported procedure. ${ }^{1}$ Wheel component with a vinyl group (2) was synthesized according to the previously reported 
procedure. $^{2-3}$ Rotaxane cross-linker with two vinyl groups (RC) was synthesized according to the previously reported procedure. ${ }^{4}$ The characterization of $\mathbf{R C}$ was carried out by the spectroscopic analyses according to the previous report. ${ }^{4}$

\section{Synthesis of cross-linked polymers}

General procedure: a photoinitiator IRGACURE ${ }^{\circledR} 500, n$-butyl acrylate (BA), and a mixture of crosslinkers were degassed three times via the freeze-thaw technique. The resulting mixture was placed on a Teflon plate and covered with a glass plate, and UV irradiated for $45 \mathrm{~min}$ at $30^{\circ} \mathrm{C}$ and then allowed to stand for $12 \mathrm{~h}$ at $30{ }^{\circ} \mathrm{C}$. The obtained gelled product was purified by repeated swelling in $\mathrm{CH}_{2} \mathrm{Cl}_{2}$ and methanol twice, followed by gentle drying at r.t. for $12 \mathrm{~h}$ and in vacuo for $12 \mathrm{~h}$ to produce the corresponding crosslinked polymer in $64-74 \%$ yield. The amounts of used reagents are shown in Table S1.

Table S1. Reaction conditions of the synthesis of cross-linked polymers

\begin{tabular}{c|cccccc|c}
\hline $\begin{array}{c}\text { Cross-linked } \\
\text { polymer }\end{array}$ & $\begin{array}{c}\text { BA } \\
{[\mathrm{mmol}]}\end{array}$ & $\begin{array}{c}\text { RC } \\
{[\mu \mathrm{mol}]}\end{array}$ & $\begin{array}{c}\mathbf{C C} \\
{[\mu \mathrm{mol}]}\end{array}$ & $\begin{array}{c}\text { Total } \\
\text { cross-linker } \\
{[\mu \mathrm{mol}]}\end{array}$ & $\mathbf{R C}: \mathbf{C C}$ & $\begin{array}{c}\text { IRGACURE } 500 \\
{[\mathbf{m g}]}\end{array}$ & $\begin{array}{c}\text { Yield a } \\
{[\%]}\end{array}$ \\
\hline RCP & 20 & 100 & 0 & $100(0.5 \mathrm{~mol} \%)$ & $100: 0$ & 200 & 64 \\
HCP_90 & 20 & 90 & 10 & $100(0.5 \mathrm{~mol} \%)$ & $90: 10$ & 200 & 73 \\
HCP_85 & 16 & 68 & 12 & $80(0.5 \mathrm{~mol} \%)$ & $85: 15$ & 160 & 70 \\
HCP_75 & 16 & 60 & 20 & $80(0.5 \mathrm{~mol} \%)$ & $75: 25$ & 160 & 74 \\
HCP_60 & 16 & 48 & 32 & $80(0.5 \mathrm{~mol} \%)$ & $60: 40$ & 160 & 74 \\
CCP & 20 & 0 & 100 & $100(0.5 \mathrm{~mol} \%)$ & $0: 100$ & 200 & 65 \\
\hline
\end{tabular}

a Calculated by weight.

\section{References}

(1) Aoki, D.; Uchida, S.; Nakazono, K.; Koyama, Y.; Takata, T. ACS Macro. Lett. 2013, $2,461$.

(2) Ashton, P. R.; Baxter, I.; Cantrill, S. J.; Fyfe, M. C. T.; Glink, P. T.; Stoddart, J. F.; White, A. J. P.; Williams, D. J. Angew. Chem., Int. Ed. 1998, 37, 1294.

(3) Iijima, K.; Kohsaka, Y.; Koyama, Y.; Nakazono, K.; Uchida, S.; Asai, S.; Takata, T. Polym. J. 2014, $46,67$.

(4) Sawada, J.; Aoki, D.; Takata, T. Macromol. Symp. 2017, 372, 115. 